Int. J. Environ. Sci. Tech.

(C) Spring 2006, Vol. 3, No. 2, pp. 191-195

\title{
Genotypic and environmental interaction in advanced lines of rice under salt-affected soils of Punjab
}

\author{
${ }^{*}$ Y. Ali, G. Sarwar, Z. Aslam and F. Hussain \\ Nuclear Institute of Agriculture and Biology, Faisalabad, Pakistan
}

Received 18 August 2005;

revised 28 December 2006;

accepted 3 March 2006;

available online 20 April 2006

\begin{abstract}
Sixteen genotypes developed through hybridization and mutation breeding techniques were evaluated during the year 2003-04 on nine locations covering most of the area of Punjab province including Faisalabad, Toba Tek Singh and Jhang. NIAB-IRRI-9, Jhona-379 salt tolerant genotypes and super Basmati, a salt sensitive variety were included as standard checks. The tested material (six genotypes) was generated by crossing fine varieties of rice viz. Basmati-370 and Basmati-385 with three coarse varieties of rice viz. NIAB-IRRI-9, Jhona-349 and NIAB-Rice-1. The mutants (seven mutants) were derived by gamma irradiation of rice varieties, Basmati-370 and Basmati-385. The nine sets of experiments were conducted in the naturally high saline sodic soils having EC range of 9.2-18.13 d/Sm pH=8.659.50 , and SAR=20.7-37.15. The seed yield data collected at maturity and stability parameters were computed to know genotypic $\mathrm{x}$ environment interaction and varietals performance. The combined analysis of variance showed highly significant variance in case of varieties, locations and varieties $x$ locations interaction. Varieties and varieties $x$ Environment (Lin) also showed highly significant differences. It means that genotypes exhibited different behavior in different locations / environments which is due to their different genetic make up. The behavior may be cross over (in which significant change in ranking occurs from one environment to another) or cross over nature (in which case the ranking of genotype remains constant across environments and the interaction is significant because of change in the magnitude of response) depending upon the ranking order of genotypes performance under different environment. In our study, only super Basmati behavior was of almost non cross over nature, while others had cross over type of interaction. Based on overall mean seed performance, mutant NIAB-Rice-4 and DM-38/88 produced significantly the highest grain yield (5.6 t/ha) followed by mutant line NIAB-Rice-5 (5.4 t/ha) and NIAB-rice-2 (5.3 t/ha). The lowest performing genotype was super Basmati (3.0 t/ha). The coarse variety Jhona-349 produced (4.8 t/ha) grain yield. Mutant line DM-38/88 showed significant regression co-efficient differences from unity while mutant line NIAB-Rice-4 showed non significant difference of regression co-efficient from unity. Mutant line, NIAB-Rice- 4 also showed non significant difference of standard deviation to regression co-efficient from zero. All the three parameters of stability i.e. overall mean seed yield, regression co-efficient and standard deviation to regression, provided clear evidence that mutant line NIAB-Rice-4 produced maximum stable yield compared to super Basmati.
\end{abstract}

Key words: Genotype, mutant, rice, dwarf, interaction, yield

*Corresponding Author, E-mail: yousaf_sem@yahoo.com

\section{INTRODUCTION}

In Pakistan rice is the premier food grain crop for domestic consumption and export abroad occupying an area of over 2.23 million hectare and production 4.48 million tones with foreign exchange return of 33 million US\$ (Economic Survey, 2002-2003). According to FAO (2000) it is very low as compared to other countries area South America, Brazil, China, India, Indonesia and Thailand 5.7, 3.7, 3.0, 4.5, 11.5, 10.0, million hectares, production 20.5, 11.2, 19.0, 13.4, 51.0 and 23.4 million tones respectively. In Pakistan, both coarse and fine varieties of rice are cultivated especially coarse in Sindh and fine in Punjab province. The production share of Punjab is $48 \%$. The present grain yield per unit area of rice is low (2892 kg/ha) in comparison with respect to the other countries of the world like Egypt ( $\left.8527 \mathrm{~kg} / \mathrm{ha}^{-1}\right)$ and USA (6354 kg/ha). There are so many factors responsible for this low yield, may be low potential variety or poor management practices including low inputs. In addition, there may be other reasons, such as soil salinity etc. The yielding ability of a variety is the result of its interaction with the prevailing environment. Environmental factors such as soil characteristics and types, moisture, sowing time, fertility, temperature, day length vary over the 
years and locations. There is strong influence of environmental factors during various stages of crop growth (Bull et al 1992), thus genotypes differ widely in their response to environments. Many research workers are of the view that average high yield should not be the only criteria for a genotype superiority unless its superiority in performance is confirmed over different type of environmental conditions (Qari et al 1990, Kinyua 1992, Golmirzaie et al 1990 and Liu et al 1992). Stability in performance of a genotype over a range of environments is a desirable attribute and depends upon the magnitude of genotype $\mathrm{x}$ environment interactions (Ahmed et al 1996). In Pakistan, 6.8 mha of land is salt-affected. Out of this, 2.67 mha is in Punjab. Slightly saline land in Punjab is 472.4; moderately saline 805 , severely saline 788 and very severe saline land is 652 thousand hectares (Anonymous 2003). So there is dire need to screen rice genotypes which have stable performance over range of salt affected lands. This will help a lot to improve and increase the rice area and production. Keeping all these factors in mind, a multilocational experiment was designed to study the performance of diverse types of rice genotypes over a range of salt affected lands.

\section{MATERIALS AND METHODS}

In a multilocational experiment to evaluate sixteen genotypes of rice developed through mutation breeding and crossing techniques was conducted in summer season at nine different locations covering most of the area of Punjab province including Faisalabad, Toba Tek Singh and Jhang during the year 2003-04. NIAB-IRRI9 and Jhona-349 salt tolerant genotypes and Super Basmati a salt sensitive variety were included as checks. The material studied (16 genotypes) was generated by crossing two fine varieties of rice viz. Basmati 370 and Basmati 385 with three coarse varieties of rice viz. NIAB IRRI-9, Jhona-349 and NIAB Rice-1. The mutant varieties (7 in number) were derived by treating Basmati 370 and Basmati 385 with gamma irradiation. The experiments were conducted on the naturally high saline sodic soils with EC ranging from 9.2-18.13 $\mathrm{dsm}^{-}$ $1, \mathrm{pH}=8.65-9.50$ and $\mathrm{SAR}=20.7-37.15$. The seed yield data were collected at maturity and subjected to analysis of variance (Steel and Torrie 1980) and stability parameters were computed following Eberhart and Russell model (1966).

\section{RESULTS}

Combined analysis of variance (Table 1) showed highly significant differences among varieties, environment, variety $\mathrm{x}$ environments interaction. Highly significant difference in the genotypes of rice under study may be due to differences in their genetic makeup and diverse nature of origin. The highly significant differences in locations indicated an existence of variation in the prevailing environments. The highly significant genotype $x$ environment ( $\mathrm{G}$ x E) interaction may be either a cross over $G$ x E interaction or a non cross over nature. In crossover, significant change in ranks occurs from one environment to another (Matus et al., 1997). In non cross over, G x E interaction, ranking of genotypes remains constant across environments and the interaction is significant because of changes in the magnitude of response (Baker, 1988, Blum, 1983 and Matus et al., 1997). Genotypes showed highly significant differences in their mean seed yield performance.

In this study, Super Basmati almost showed non cross over nature $\mathrm{G}$ x $\mathrm{E}$ interaction while other genotypes had cross over type of $\mathrm{G} x \mathrm{E}$ interaction. Varieties also showed highly significant differences in case of pooled analysis of variance (Table 2). Partitioning of genotype $\mathrm{x}$ environment interaction revealed highly significant difference in case of Var. $\mathrm{x}$ Env. (Lin) and non- linear (pooled deviation) interaction.

Table 1: Combined analysis of variance for rice 2003-04

\begin{tabular}{clccccc}
\hline Values & Source & $\begin{array}{c}\text { Degree of } \\
\text { freedom (d. f) }\end{array}$ & $\begin{array}{c}\text { Sum of squares } \\
\text { (s. s) }\end{array}$ & $\begin{array}{c}\text { Mean square } \\
\text { (m. s) }\end{array}$ & F value & Prob. \\
\hline 1 & Replication & 2 & 0.056 & 0.028 & 2.4069 NS & 0.0919 \\
2 & Factor A(Var.) & 15 & 155.866 & 10.391 & $897.8152 * *$ & 0.0000 \\
4 & Factor B (Env.) & 8 & 23.570 & 2.946 & $254.5627^{* *}$ & 0.0000 \\
6 & AB (Var.x Env.) & 120 & 34.790 & 0.290 & $25.0498^{* *}$ & 0.0000 \\
7 & Error & 286 & 3.310 & 0.012 & & \\
& Total & 431 & 217.593 & & & \\
\hline
\end{tabular}


Table 2: Pooled analysis of variance for rice 2003-04

\begin{tabular}{lcccc}
\hline \multicolumn{1}{c}{ Source } & $\begin{array}{c}\text { Degree of } \\
\text { freedom (d. f) }\end{array}$ & $\begin{array}{c}\text { Sum of squares } \\
\text { (s. s) }\end{array}$ & $\begin{array}{c}\text { Mean square } \\
\text { (m. s) }\end{array}$ & F. Value \\
\hline Total & 143 & 71.415 & 0.499 & \\
Environments & 8 & 7.856 & 0.982 & $58.377^{* *}$ \\
Varieties & 15 & 51.961 & 3.464 & \\
Varieties x Environment & 120 & 11.597 & 0.097 & \\
Environment + Varieties x Environment & 128 & 19.454 & 0.152 & $5.562^{* *}$ \\
Environment (Lin) & 1 & 7.857 & 7.857 & $4.945^{* *}$ \\
Varieties x Environment (Lin) & 15 & 4.951 & 0.330 & \\
Pooled Deviation & 112 & 6.646 & 0.059 & \\
Pooled Error & 288 & 3.456 & 0.012 & \\
\hline
\end{tabular}

These highly significant differences are very important for determining $\mathrm{G}$ x E interaction. Relatively higher value of the linear component as compared to non-linear one, suggested the possibility of prediction of performance for seed yield over the environments. High values of linear components as compared to non linear have been reported by many workers (Khan et al., 1987, Yadav and Tomar 1985 and Khan 1988). Over all mean seed yield performance (Table 3 ) showed significant differences. Mutant DM-38/88, NIAB-IRRI-9 and NIAB-Rice-4 produced significantly the highest seed yield ( $5.6 \mathrm{t} / \mathrm{ha}$ ) followed by mutant line NIAB-Rice-5 (5.4 t/ha). The lowest performing genotype was super Basmati (3.0 t/ha). This may be due to its more sensitiveness to salt and non adaptiveness in these conditions. The coarse variety Jhona- 349 produced ( $4.8 \mathrm{t} / \mathrm{ha}$ ) seed yield. Overall, most of the material except cross combination NIAB-6 x DM-25, Shaheen-Basmati, NIAB-RICE-3, Jhona-349, Bas-385xNIAB-6, DM 3-89 and Super Basmati produced highest seed yield as compared to standard or general mean (4.96 t/ha). Genotype DM-38/88 and DM-5-89 showed significant differences while NIAB-Rice-5, Supper- basmati, Shaheen basmati and NIAB-IRRI-9 showed highly significant difference of regression coefficient than unity. Nine out of sixteen genotypes under study showed highly significant and two showed significant differences from zero in case of standard deviation to regression coefficient (Table 3). Lin et al. (1986) pointed out that large deviation from regression coefficient should not be considered as a measure of stability but should be taken as an indication of the inadequacy of the model to estimate stability. Finley and Wilkinson (1963) computed for each variety a linear regression of its yield on the mean yield of all varieties for each location. According to him a stable variety is the one for which the regression coefficient does not differ from zero (i.e. bi = o within the limits of sampling error) and thus, stability is defined as the consistency in performance of a variety over varying environments. In Eberhart and Russell model (1966) regression coefficient (bi) is considered as parameters of response and $\mathrm{S}^{2} \mathrm{~d}$ as the parameters of stability. For a given value of independent variable, the value for dependent variable may be estimated using the regression equation, provided $S^{2} d$ is not significantly different from zero. Assuming $S^{2} d=0$, a high value of bi will mean more change in y for a unit change in 1 in other words, the variety is more responsive. Such variety may, therefore, be recommended only for highly favourable environments, e.g. under high fertility conditions. A relatively lower value of bi, say around 1 , will mean less responsive to the environmental change and therefore, more adaptive. If, however, bi is negative the variety may be grown only in poor environment. $S^{2} d$, if significant from zero, will invalidate the linear prediction. If $S^{2} d$ is non significant, the performance of a genotype for a given environment may be predicted. Accordingly, a variety whose performance can be predicted (i.e. $\mathrm{S}^{2} \mathrm{~d}=0$ ) is said to be stable. Thus, the stability (consistent performance of a variety over environments), as conceived by Finley and Wilkinson (1963) does not hold true in this case. Here stability means predictability. Stability analysis has also been carried out by other scientists in many crops such as wheat (Sial et al., 2000 and Mehta et al., 2000) barley (Romagosa et al., 1999), bermuda grass (Chakroun et al., 1990), oat (Helm, 1993), lentil (Sarwar et al., 2003) and in cowpea (yousaf et al., 2004). Mutant line DM-38/88 showed significant regression 
Table 3: Stability parameter of rice genotypes tested under various environments

\begin{tabular}{cllll}
\hline Sr. \# & Varieties Name & $\begin{array}{c}\text { Mean Seed Yield } \\
(\text { ton/ha })\end{array}$ & $\begin{array}{c}\text { Regression co- } \\
\text { efficient }(\mathrm{bi})\end{array}$ & $\begin{array}{c}\text { Standard deviation to } \\
\text { regression } \\
\left(\mathrm{Sd}^{2}\right)\end{array}$ \\
\hline 1 & NIAB-Rice-2 & $5.301 \mathrm{C}$ & 1.751 & $0.076^{* *}$ \\
2 & DM-38/88 & $5.634 \mathrm{~A}$ & $0.476^{*}$ & 0.017 \\
3 & NIAB-Rice-4 & $5.594 \mathrm{~A}$ & 1.335 & $0.051^{* *}$ \\
4 & DM-25xNIAB-6 & $5.120 \mathrm{E}$ & 1.318 & $0.056^{* *}$ \\
5 & NIAB-6xDM-25 & $4.816 \mathrm{I}$ & 0.810 & $0.218^{* *}$ \\
6 & DM-3-89 & $4.868 \mathrm{HI}$ & 0.618 & $0.029^{*}$ \\
7 & Jhona-349xBas-370 & $5.033 \mathrm{~F}$ & 1.276 & $0.093^{* *}$ \\
8 & NIAB-Rice-3 & $4.881 \mathrm{GH}$ & 1.634 & $0.061^{* *}$ \\
9 & Jhona-349 & $4.808 \mathrm{I}$ & 0.282 & $0.019^{* *}$ \\
10 & NIAB-Rice-1 & $4.936 \mathrm{G}$ & 1.015 & 0.012 \\
11 & Bas-385xNIAB-6 & $4.888 \mathrm{GH}$ & 1.223 & $0.077^{* *}$ \\
12 & DM-5-89 & $5.181 \mathrm{D}$ & $2.269^{*}$ & $0.077^{* *}$ \\
13 & NIAB-Rice-5 & $5.378 \mathrm{~B}$ & $2.467^{* *}$ & 0.008 \\
14 & Super Basmati & $3.070 \mathrm{~K}$ & $-0.212^{* *}$ & $0.032^{*}$ \\
15 & Shaheen Basmati & $4.261 \mathrm{~J}$ & $-0.031^{* *}$ & 0.006 \\
16 & NIAB-IRRI-9 & $5.609 \mathrm{~A}$ & $-0.229^{* *}$ & \\
\hline
\end{tabular}

Mean in the same column sharing the letters did not differ significantly according to DMRT (P-0.05)

coefficient differences from unity. Compared to this, mutant line DM-5-89 and NIAB-Rice-5 exhibited non significant difference of regression coefficient from unity. The mutant line NR-1 and Basmati-385xNIAB-6 showed non-significant differences of standard deviation to regression coefficient from zero. In this study nine genotypes showed highly significant difference in the values of standard deviation to regression. Two lines have the value of standard deviation to regression significantly different from zero. Five showed the values of standard deviation to regression non-significantly different from zero. Lin et al 1986 pointed out that large deviation from regression co-efficient showed not be considered as a measure of stability but should be taken as indication of the inadequacy of the model to estimate stability.

\section{DISCUSSION AND CONCLUSION}

Mutant line DM-38-88 showed significantly regression coefficient differences from unity. This produced ( $5.6 \mathrm{t} / \mathrm{ha}$ ) the highest yield and can be grown in rich or favourable environment. Variety NIAB-IRRI9 also gave similar results as DM-38-88. All the three parameters of stability i.e. overall high mean seed yield, regression coefficient and standard deviation to regression, provided clear evidence that the mutant line NIAB-Rice- 4 produced maximum stable yield compared to Super Basmati. The other high yielding genotype like DM-38/88 (5.68 t/ha) which had regression coefficient significantly different from one or unity may be suitable for growing in rich or favorable environment. From these results of stability it may be concluded that in the type of saline soils as studied here, the newly evolved mutant line NIAB-Rice-4 may be grown successfully for obtaining more economical yield potential without facing any major drawback of adaptation to this in particular saline area. Furthermore, these studies provided a clue that breeding techniques other than conventional (mutation breeding) could be successfully employed for the induction of variation to select the new genotypes with improved agronomic and physiological characters suitable for stress environment like salinity.

\section{REFERENCES}

Ahmad, J., Chaudhry, M. H., Salah-ud-Din, S. and Ali, M. A., (1996). Stability for grain yield in wheat. Pak. J. Bot., 28,6165.

Ali, Y., Aslam, Z., Hussain, F. and Shakur, A., (2004). Genotype and environmental interaction in cowpea (Vigna unguiculata L) for yield and disease resistance. Int. J. Environ. Sci. Tech., 1(2): 127-131

Anonymous, Economic Survey, (2002-2003). Government of Pakistan, Finance division, Economic adviser's wing, Islamabad.

Anonymous, FAO production year book, (2000). 54, 76-77. Anonymous. 2001. Agri. Statistics of Pakistan. Ministry of Food and Agri; Pakistan.

Baker, R. J., (1988). Test for crossover genotypeenvironmental interaction. Can. J. Plant Sci., 68, 405-410. 
Blum, A., (1983). Genetic and physiological relationship in plant breeding for drought resistance. In: Plant production and management under drought conditions (Eds.): J. T. Stone and W. O. Willis. Elsevier Amsterdam, 195-205.

Bull, J. K., Cooper, M., Delacy, I. H., Bassford, K. E. and Woodruff, D. R., (1992). Utility of repeated checks for hierarchical classification of data from plant breeding trials. Field Crop. Res., 30, 79-95.

Chakroun, M., Taliaferro, C. M. and Mc.New, R. W. (1990). Genotype-environment interaction of Bermuda-grass forage yield. Crop. Sci., 30, 49-53.

Eberhart, S. and Russell, W. A., (1966). Stability parameters for comparing varieties. Crop Sci., 6, 36-40.

Finlay, W. and Wilkinson, G. N., (1963). The analysis of adaptation in a plant breeding programme. Aust. J. Agric. Res., 14: 742-754.

Golmirzaie, A. M., Schmidt, J. W. and Dreier, A. F., (1990). Components of variance and stability parameters in studies of cultivars $\mathrm{x}$ environment interaction in winter wheat (Triticum aestivum L.). Cereal Res. Communicat., 18, 249256.

Helms, T. C., (1993). Selection for yield and stability among oat lines. Crop. Sci., 33, 423-426.

Khan, I. A., Malik, B. A. and Bashir, M., (1988). Investigation of genotype $\mathrm{x}$ environment interaction for seed yield in chickpea (Cicer arietinum L.). Pak. J. Bot., 20, 201-204.

Khan, I. A., Malik, B. A. and Tahir, M., (1987). Phenotypic stability for yield in chickpea. Pak. J. Sci. Ind. Res., 309, 455-456.

Kinyua, M. G., (1992). Genotype x environment effects on bread wheat grown over multiple locations and years in Kenya. In: $7^{\text {th. }}$ regional wheat workshop for Eastern, Central and Southern Africa Nakuru Kenya, 103-107.

Lin, C. S., Binns, M. R., Lefkovitch, L. P., (1986). Stability analysis: Where do we stand? Crop. Sci., 26, 894-900.
Liu, L. X., Haung, T. C., Liu, G. T. L. and Zhang, S. Z., (1992). Stability analysis of yield and quality characters of hybrid and pure line winter wheat cultivars. Acta. Agronomic. Sinica., 18, 38-49.

Matus, A., Slinkard, A. E. and Kessel, C. V., (1997). Genotype $\mathrm{x}$ environment interaction for carbon isotope discrimination in spring wheat. Crop Sci., 37, 97-102.

Mehta, H., Sawhney, R. N., Singh, S. S., Chaudhry, H. B. Sharma, D. N. and Sharma, J. B., (2000). Stability analysis of high yielding wheat at varying fertility levels. Indian J. of Genet. Plant Breed., 60, 471-476.

Qari, M. S., Khan, N. I. and Bajwa, M. A., (1990). Comparison of wheat cultivars for stability in yield performance. Pak. J. Agri. Res., 11,73-77.

Romagosa, I., Ullrich, S. E., Han, F. and Hayes, P. M., (1996). Use of the additive main effects and multiplicative interactions in QTL mapping for adaptation in barley. Theor. Appl. Genet., 93, 30-37.

Sarwar, G., Sadiq, M. S., Saleem, M. and Abbas, G., (2003). Genotype $\mathrm{x}$ environment interaction in newly developed lentil germplasm under cotton based cropping system. Proc. of Seminar Sustainable utilization of plant genetic resources for agricultural production, NARC Islamanad, 219-226.

Sial, M. A., Arain, M. A. and Ahmad, M., (2000). Genotype x environment interaction on bread wheat grown over multiple sites and years in Pakistan. Pakistan J. Botany, 32, 85-91.

Steel, R.G.D., and J.H.Torrie. 1980. Principles and Procedures of Statistics. Mc Graw Hill Book Company, Inc. New York.

Y. Ali, Aslam, Z., Hussain, F. and Shakur, A., (2004). Genotype and environmental interaction in cowpea (Vigna unguiculata L) for yield and disease resistance. Int. J. Environ. Sci. Tech., 1(2): 127-131.

Yadav, R. S. and Tomar, P. S., (1985). Protein content and stability in blackgram. Ind. J. Agri. Sci., 55, 510-512.

\section{AUTHOR(S) BIOSKETCHES}

Ali, Y., Nuclear Institute of Agriculture and Biology, Faisalabad, Pakistan.

E-mail:yousaf_sem@yahoo.com

Sarwar, G., Nuclear Institute of Agriculture and Biology, Faisalabad, Pakistan.

E-mail: sarwarniab@yahoo.com

Aslam, Z., Nuclear Institute of Agriculture and Biology, Faisalabad, Pakistan.

E-mail: zaslamniab@yahoo.com

Hussain, F., Nuclear Institute of Agriculture and Biology, Faisalabad, Pakistan.

E-mail: fhussainfsd@yahoo.com

This article should be referenced as follows:

Ali, Y., Sarwar, G., Aslam, Z. and Hussain, F. , (2006). Genotypic and environmental interaction

in advanced lines of rice under salt-affected soils of Punjab. Int. J. Environ. Sci. Tech., 3 (2), 191-195. 